\title{
BOTANDO CORPO, (DES)FAZENDO GÊNERO. UMA FERRAMENTA PARA A PESQUISA-INTERVENÇÃO NA EDUCAÇÃO
}

Fernando Altair Pocahy ${ }^{1}$

\begin{abstract}
Resumo
Esse artigo apresenta o percurso de experimentação de uma metodologia de pesquisaintervenção no campo da educação escolar, com ênfase para o estudo das relações de gênero, sexualidade e gerações em interseccionalidades com outros marcadores sociais de identidade e diferença. Buscou-se com o presente estudo compreender como determinadas posições de sujeito se produzem e quais mecanismos de inteligibilidade e negociações de significados encontram-se presentes em determinados contextos da educação escolar, no mesmo instante em que nos alojamos na perspectiva tática da reversibilidade das formas de objetivação das subjetividades e das desigualdades sociais decorrentes destes discursos através da formulação de ferramentas para a pesquisa-intervenção. Os resultados dessa experimentação metodológica apontam que pesquisa-intervir pode funcionar no sentido de alerta a que estamos ativamente envolvidos na disputa dos processos de significação do corpo, gênero e sexualidade cotidianos.
\end{abstract}

Palavras-chave: Corpo; Gênero; Sexualidade; Interseccionalidade; Educação

Esse trabalho reflete uma parte das análises de um percurso de formação teóricometodológica e de (re)definição de uma ferramenta para a pesquisa-intervenção no âmbito das relações de gênero, sexualidade e geração em interseccionalidade com outros marcadores sociais e de identidade e diferença (SILVA, 2007) na educação. Os avanços nessa experimentação metodológica foram possíveis a partir de uma pesquisa em formação de pós-

\footnotetext{
${ }^{1}$ Doutor em Educação (UFRGS), Endereço: Rua São Francisco Xavier, 524, Sala 12.037, Maracanã, Rio de Janeiro - RJ, Brasil. Endereço eletrônico: pocahy@uol.com.br
} 
doutorado $^{2}$ vinculada a um núcleo de pesquisas propositivo em estudos e intervenções em gênero e sexualidade, situado na Região Sul do Brasil. Por ocasião desse trabalho, tivemos a oportunidade de lançar mão de distintas abordagens e técnicas no desenvolvimento de uma pesquisa que pretendia contribuir com os movimentos de transformação de dada relação social marcada pela interpelação normativa de gênero, sexualidade e idade, ao mesmo instante em que tivemos a chance de assumirmos colocarmos em andamento práticas de produção de conhecimento (POCAHY, 2006; POCAHY, 2007).

Os resultados de pesquisa em tela foram produzidos a partir da análise de oficinas específicas sobre relações de gênero em interpelação etária (BOZON, 2009). Essas oficinas foram denominadas "botando corpo, (des)fazendo gênero". Através delas, ao se fazer uso da ferramenta da "tatuagem de representações" (busca ativa de representações sociais disponíveis em artefatos culturais, como revistas e jornais) e da performance da narrativa coletiva (a construção de histórias sobre o "corpo tatuado de representações"), estabelecemos condições de problematização para o estudo das relações de gênero no campo amplo da educação, com ênfase para a proposição de tecnologias de intervenção-pesquisa na escola.

\section{UMA AGONÍSTICA DA EDUCAÇÃO ESCOLAR: O(S) GÊNERO(S) EM DISPUTA}

Embora não seja o único lugar onde se articulam disputas de significados sobre corpo, gênero e sexualidade, a escola é, seguramente, um importante contexto de experimentações dessas tensões. É no entre-mundos da escola por onde perduram e/ou são contestadas algumas das formas de conhecer articuladas às políticas de gestão da vida humana (FOUCAULT, 1976/2001) articuladas aos dispositivos de gênero e sexualidade.

Nesse sentido, consideramos a educação escolar como um plano de subjetivação onde são acionadas práticas divisoras, um espaçotempo onde pessoas e instituições estabelecem relações a partir de determinados códigos morais em ação no seu lugar-de-vida. Essa ideia, derivada ds estudos foucaultianos, nos permite (re)afirmar que estamos em um espaço de produção de subjetividades, vidas engendradas e posições de sujeito forjadas a partir de determinados de jogos de verdade (FOUCAULT, 1984/2001) - tais quais os códigos que dizem respeito ao dispositivo da sexualidade e/ou às epistemologias de fabricação cultural do

\footnotetext{
${ }^{2}$ Agradecimentos especiais à Professora Dra. Miriam Pillar Grossi pela acolhida e acompanhamento durante a minha permanência na Universidade Federal de Santa Catarina - UFSC e aos/às colegas NIGS - Núcleo de Pesquisas em Identidades de Gênero e Subjetividade/ Projeto Papo Sério; e à CAPES, através do Programa CAPES-Reuni, pela possibilidade de realização desta pesquisa de pós-doutoramento.
} 
BOTANDO CORPO, (DES)FAZENDO GÊNERO.

\section{UMA FERRAMENTA PARA A PESQUISA-INTERVENÇÃO NA EDUCAÇÃO}

corpo-subjetividade gendrada ou racializada.

Ao considerarmos essa perspectiva a escola não se constitui somente como superfície onde poderíamos constatar a diversidade de corpos-vidas. A escola é, sobretudo, espaço agonístico $^{3}$, uma das instâncias na cultura a produzir e moderar estes engendramentos discursivos, deixando suas marcas evidentes - materialidades expressas na figura de um/a 'diferente' - em constante disputa e ressignificação.

Nesses termos, assumimos a noção de currículo - com suas práticas pedagógicas, sua vida e saberes-fazeres praticados - na direção em que podemos perceber a escola como espaçotempo de disputas sobre o humano - uma noção de humano. Arranjos disciplinares, reificados por (bio)políticas estatais e também pelos saberes acadêmicos que formam educadoras e educadores, não são vividos-praticados sem contestação e dissidência. Essa forma de pensar a escola e seus praticantes não pode ser descolada da noção de resistência, insubordinação e recusa. Não é possível imaginar a escola e seus/suas praticantes como figuras passivas diante de um jogo de poder (supostamente exterior a elas/eles). Elas/eles (os/as praticantes dos cotidianos escolares) fazem o jogo agonizar, com a produção de epistemologias contextualizadas na cultura que eles/elas mesmos/mesmas movimentam, (re)inventam. É dessa reflexão que resulta a perspectiva aqui em análise de conceber os currículos praticados nas escolas são tecidos em redes, redes de significação, redes de saberes-práticas, redes de subjetividades (ALVES, 2001).

Este modo de perceber as relações sociais que interpelam múltiplas posições de sujeito-escola faz emergir a necessidade de compreender o campo amplo das relações institucionais e das políticas públicas que definem as condições de circulação de determinados enunciados sobre a educação. Acompanhar a emergência e a circulação desses enunciados nos permite compreender os processos de subjetivação que nos fazem acreditar que somos isso ou aquilo, interpelados/as pelas lógicas binárias que (ainda) restam da modernidade. Isto é, a escola - uma determinada comunidade escolar - não pode ser unicamente o objeto de comprovação das objetivações discursivas a que está interessado/a saber o pesquisador/ a pesquisadora. A escola é também e de outra forma uma interlocutora que não somente tem algo a dizer, mas é espaço-tempo-lugar de saberes-fazeres-sabores que engendra nos seus/ com os seus cotidianos. Por esse motivo conduzimo-nos no sentido de pesquisar desde uma

\footnotetext{
${ }^{3}$ Um jogo/disputa que envolve "incitação recíproca e de luta; tratando-se, menos de uma oposição de termos que se bloqueiam mutuamente do que de uma provocação permanente" (FOUCAULT, 1995, p.245).
} 
disposição ética que respeite os/as praticantes de uma determinada comunidade escolar - de um determinado cotidiano escolar -, assumindo que eles/elas têm papel de protagonistas nesse processo e que não seriam figuras subjugadas aos saberes de outrem (no caso, especialistas em geral e mesmo pesquisadores/ras).

A partir deste viés analítico político, institucional e cultural, alojamo-nos na perspectiva de construir outros caminhos investigativos (COSTA et al 2005), desejamos outros encontros com o "objeto de pesquisa". Assim, a possibilidade de engajar o esforço crítico da pesquisa a uma ação de extensão de reconhecido exercício de diálogo com as comunidades escolares locais da cidade de Florianópolis, ofereceu-nos condições para a efetivação de experimentar/usufruir de "desvios" e "descaminhos" metodológicos, exercendo alguma inventividade na formulação da metodologia de pesquisa-intervenção no caminho implicado com as vozes ditas subalnertizadas pelas objetificações discursivas expressas em sexismo, racismo e LGBTfobias.

\section{ARTICULAÇÕES METODOLÓGICO-CONCEITUAIS NA PESQUISA-IN(TER)VENÇÃO}

Inicialmente a proposta de trabalho de pesquisa se dirigiu à problematização sobre o status ontológico de uma determinada forma de experimentação poltico-pedagógica na educação escolar, interseccionada nos marcadores geracionais (juventude) e de gênero - e em perspectiva de compreender essa relação com a sexualidade. Cabe ressaltar, segundo Bilge (2009), que a ideia de interseccionalidade vai além de um simples reconhecimento da multiplicidade de sistemas de opressão, ela opera por consubstancialidade. Isso significa pensar as interações na produção e reprodução das desigualdades sociais, analisando-as a partir dos regimes discursivos que produzem identidade e diferença (SILVA, 2007) e não apenas a adição de marcadores.

No curso do nosso trabalho de in(ter)venção, aos poucos demo-nos conta da necessidade de uma ação reflexiva sobre o processo metodológico, acionada às problematizações sobre corpo, gênero, sexualidade e idade. Assumimos nosso compromisso enquanto intelectuais engajadas e engajados no enfrentamento ao heterossexismo, ao racismo e outras formas arbitrárias e hierarquias sociais. Dessa forma, posicionamo-nos taticamente enquanto sujeitos que produzem um conhecimento no instante em que lutam, situados nesses enfrentamento epistemológico a partir do reconhecimento de suas próprias marcas de gênero, 
BOTANDO CORPO, (DES)FAZENDO GÊNERO.

\section{UMA FERRAMENTA PARA A PESQUISA-INTERVENÇÃO NA EDUCAÇÃO}

sexualidade, idade, raça, classe...

Tendo assumido essa proposta, elaboramos oficinas para o trabalho de investigação e estudo metodológico, considerando-se dois importantes aspectos: a) a perspectiva de que estávamos/estamos interessados/as em conhecer algo que nos mobilizava ética, estética e politicamente; e b) o fato de que estamos implicados/as duplamente com o trabalho no campo das relações sociais de gênero e sexualidade - seja porque se trata de um projeto de pesquisa engajada, seja porque, pragmaticamente, a pesquisa foi possível desde o acoplamento a uma ação de extensão compreendida na perspectiva da indissociabilidade ensino-pesquisaextensão e situada desde um núcleo universitário que tem por compromisso o enfrentamento ao heterossexismo, o racismo e outras formas violentas e arbitrárias de regulação social e objetivação das subjetividades.

A metodologia de pesquisa-intervenção foi acionada por acreditarmos que essa modalidade de atuação participante poderia permitir ao pesquisador condições mais ou menos sistematizadas e conceitualmente definidas para agir-pesquisar-agir diante das objetivações discursivas presentes nos contextos das relações de gênero e sexualidade na escola. Com isso, tratamos de privilegiar uma abordagem específica de intervenção social em articulação com as práticas extensionistas e de pesquisa (pós-)crítica.

Consideramos que a reflexão metodológica em torno das oficinas poderia funcionar como uma sorte de experimentação epistemológica capaz de produzir (algumas) fissuras discursivas diante dos tradicionais métodos de pesquisa que operam sobre e não com as pessoas e instituições. Vimos especialmente na possibilidade de que vozes subalternas (SPIVAK, 2002) se pronunciassem diante do regime normativo de gênero e das prescrições da sexualidade um espaçotempo outro, capaz de fomentar processos educativos horizontais atentos aos processos de produção da diferença e desigualdade.

As oficinas intituladas "botanto corpo, (des)fazendo gênero", objeto específico desse trabalho, funcionaram como um fazer pesquisa itinerante, pontual e localizado no contexto da abrangência do projeto de extensão (algumas escolas na rede pública da cidade de Florianópolis). A partir da pesquisa com interlocutoras e interlocutores da educação escolar trabalhamos (no sentido plural, uma vez que se constituiu uma equipe para as intervenções) sobre determinados artefatos culturais ${ }^{4}$ (na forma de recortes de revistas, jornais, etc., como

\footnotetext{
${ }^{4}$ Abordamos aqui os artefatos culturais a partir da perspectiva de representação na medida em que inventam sentidos que "circulam e operam, nas arenas culturais onde o significado é negociado e as hierarquias são
} 
restos midiáticos), a fim de elaborarmos um planos de problematização a partir de restos e rastros das imagens que forjam a trama da inteligibilidade corpo-gênero- sexualidade.

Nesse instante de prática itinerante encontramos a possibilidade de pesquisar as representações de gênero em suas interseccionalidades geracionais, étnico-raciais e de localidade, entre outras, em perspectiva lúdica e estratégica. Lúdica porque a própria técnica, como afirmaremos, leva o jeito de "brincar", fazendo pesquisa de forma criativa. E estratégica porque ao mesmo tempo obtínhamos condições de intervir (considerando-se que o contrato das oficinas era aquele do Projeto Papo Sério, cujos objetivos se dirigem ao enfrentamento das violências sexistas, lgbtfóbicas, racistas, entre outras) em um processo de negociação contínua com estas interlocutoras e interlocutores jovens.

Decorre desta perspectiva o argumento de que temos no campo da pesquisaintervenção (em especial na sua articulação com o contexto de extensão) condições de possibilidade de compreender ao mesmo tempo em que intervir sobre uma determinada realidade social, instituída em seus modos culturais:

Como pesquisadores do campo das ciências humanas, nosso perguntar indaga sobre os modos de viver, de existir, de sentir, de pensar próprios de nossa ou de outras comunidades de sujeitos. O próprio fato de perguntar produz, ao mesmo tempo, tanto no observador quanto nos observados, possibilidades de auto-produção, de autoria. Nossos "objetos de pesquisa" também são observadores ativos, produzem outros sentidos ao se encontrarem com o pesquisador, participam de redes de conversações que podem ser transformadas a partir de novas conexões, novos encontros. (MARASCHIN, 2004; p.104)

Essa posição de pesquisa ao mesmo tempo em que intervém, produz um conhecimento. Segundo Rocha e Aguiar (1999; 2003), pesquisa-intervenção é uma ação que:

(...) aprofunda a ruptura com os enfoques tradicionais de pesquisa e amplia as bases teórico-metodológicas das pesquisas participativas, enquanto proposta de atuação transformadora da realidade sociopolítica, já que propõe uma intervenção de ordem micropolítica na experiência social. (2003, p.67).

A questão que modulou o esforço desse trabalho de definição metodológica foi a de como articular a pesquisa ao trabalho de intervenção (aqui em um território de extensão e a partir de seus contratos tácitos com as comunidades escolares), tendo como principio ético condutor a participação ativa das interlocutoras e dos interlocutores. Tivemos como objetivos centrais ampliar os recursos da pesquisa, democratizando seus métodos - aproximando 
BOTANDO CORPO, (DES)FAZENDO GÊNERO.

\section{UMA FERRAMENTA PARA A PESQUISA-INTERVENÇÃO NA EDUCAÇÃO}

interlocutoras e interlocutores nesse caminho que se faz também ao andar. Considerando que mais do que nos informar sobre uma determinada questão de sociedade, as interlocutoras e interlocutores que contribuem com nossos problemas de pesquisa nos ajudam a compreender o que estamos (todas e todos nós) fazendo de nós mesmos, construindo conosco os problemas e as alternativas de entendimento em nosso espaço-tempo de encontro. Essa (des)arrumação de pesquisa corresponderia a noção já citada de pesquisar com e não sobre (alguém ou uma instituição, grupo).

O objetivo do trabalho com as oficinas "botando corpo, (des)fazendo gênero" foi efetivamente o de produzir alguns tensionamentos acerca de movimentos que apontam para as regulações estabelecidas na direção da constituição de uma "inteligibilidade do humano", materializadas discursivamente no amalgama corpo(sexo)-gênero-sexualidade (BUTLER, 2005; 2006) e idade (além de outras intersecções particulares). Desse modo, pareceu estratégico pensar como a idade cria condições de inteligibilidade para o que definimos em nossas sociedades ocidentais (pós) modernas como humano em termos de gênero, sexualidade e "raça"/etnia. Compartilhamos dessa forma a premissa de Lagrave (2009) quando afirma que a idade pode ser pensada como uma categoria política, histórica e contingente como o é gênero, classe social, sexualidade ou 'raça'. Isto significa que a idade organiza a vida ao conferir status de 'humanidade' em diferentes formas e condições político-culturais. E, no mesmo instante, gênero e sexualidade se tornam visíveis e possíveis nesta trama discursiva, fixando por consequência direta as possibilidades para cada idade da vida (POCAHY, 2011).

No rastro dessa reflexão sobre o projeto (bio)político que marca e produz o dispositivo da idade na experiência geracional, são muitas as inquietações que nos tocam: o que deve o sujeito contemporâneo à sua idade e quais são as hierarquias produzidas em nosso tempo para inteligibilidade e reconhecimento social? O que pode uma vida com a sua idade? O que pesa e o que conta a idade que levamos? Pode um sujeito existir - oferecer inteligibilidade social sem a sua idade? E uma idade pode ser a mesma de uma geração a outra? O que o corpo deve aos regimes políticos na gestão da vida (gendrada) na trama discursiva das fases de vida como a adolescência e/ou juventude? (POCAHY, 2012).

Em relação à regulação da vida pelas idades, consideramos esta em sua potencialidade discursiva. Entendemos a idade como materialidade em negociações culturais e desde regimes de verdade denominados, segundo Foucault (1976) como biopolítica: 
El otro campo de intervención de la biopolitica va a ser todo un conjunto de fenómenos, de los cuales algunos son universales y otros accidentales pero que, por una parte, nunca pueden comprimirse por entero, aunque sean accidentales, y que también entrañan consecuencias análogas de incapacidad, marginación de los individuos, neutralización, etc. Se tratará del problema de la vejez, muy importante desde principios desde siglo XIX (en el momento de la industrialización), del individuo que, por consiguiente, queda fuera del campo de capacidad, de actividad. Y, por otra parte, los accidentes, la invalidez, las diversas anomalías. En relación con estos fenómenos, la biopolitica va a introducir no sólo instituciones asistenciales (que existían desde mucho tiempo atrás) sino mecanismos mucho más sutiles, económicamente mucho más racionales que la asistencia a granel, a la vez masiva y con lacunas, que estaba esencialmente asociada a la Iglesia. Vamos a ver mecanismos más racionales, de seguros, de ahorro individual y colectivo, de seguridad, etcétera. (2006 [1976], p. 221).

Salientamos que as formas como as pessoas movimentam suas vidas diante dos jogos biopolíticos (na ideia foucaultiana da normalização da vida e gestão das populações) são ainda marcadas pela desigualdade nas posições de sujeito que passam a ocupar a partir das interpelações de gênero, raça, idade, sexualidade, localidade... Segundo Meyer e Damico (2006):

\footnotetext{
(...)determinadas práticas corporais que as jovens desenvolvem para cuidar do corpo, entendendo-as como práticas informadas por, e sintonizadas com, regras de normalidade socialmente instituídas e legitimadas no interior das quais o corpo emerge como território e, ao mesmo tempo, como um potente operador de diferenciações: ele é entendido e vivido tanto como o lugar de inscrição da identidade e da diferença quanto como referência de sistemas de classificação e hierarquização social. (p.107).
}

O modo como meninas e meninos são percebidas/percebidos no exercício de sua sexualidade apresenta hierarquias indeléveis. Sabemos que as meninas que ousam protagonizar sua sexualidade através de práticas de embelezamento corporal ou de práticas de investimento afetivo-sexual, seguidamente são tachadas de "piranhas", "fáceis" e “disponíveis". De acordo com a pesquisa realizada por Grossi et al (2009), observa-se um jogo de regulações e disciplinamento dos desejos de meninas tendo sobre "sua conduta pessoal um maior rigor em matéria de cuidado com o comportamento sexual do que os jovens meninos.” p.94).

As pedagogias exercidas na ficção (compulsoriedade de um ideal de gênero a ser incorporado - corporificado) dos corpos de mulheres reforça de forma contundente o sexismo e a objetificação veiculadas em discursos que hierarquizam as possibilidades de autonomia e de liberdade das mesmas, mas estes não são discursos fixos ou imutáveis. Essas inscrições nos corpos são contingentes, localizadas e provisórias, como afirmam Meyer e Damico (2006). 
BOTANDO CORPO, (DES)FAZENDO GÊNERO.

\section{UMA FERRAMENTA PARA A PESQUISA-INTERVENÇÃO NA EDUCAÇÃO}

Elas funcionam tanto para a definição de corpos de mulheres, quanto para a definição de corpos de homens, impondo a ideia de que somos sempre isso ou aquilo - homens ou mulheres e, enquanto tais, signatários de uma padrão de gênero e sexualidade.

Por outro lado, diante das produtivas críticas do pensamento queer (LOURO, 2004), compreendemos que majoritariamente operamos em nossas sociedades ocidentais modernas através dos binarismos de gênero, inteligíveis através das marcas corporais que nos definem como homens ou mulheres, como se fossem estas as únicas possibilidades (efetivamente duas dentro de uma representação universal, impraticável e irrealizável no cotidiano e desde a pluralidade de culturas).

Assim, como questão de pesquisa-intervenção acentuamos a busca pelas formas como são produzidos os corpos e as significações (en)gendradas no plano das sociabilidades juvenis, desde os territórios educacionais escolares, através do cerco das pedagogias de gênero e sexualidade presentes na mídia e desde a reflexão que nossas interlocutoras e interlocutores fazem desses discursos (binários, racializados, marcados por distinções de classe, normas de gênero e sexualidade, etc.), a partir de suas práticas e desde seus contextos.

\section{OFICINANDO PROBLEMATIZAÇÕES COM UMA FERRAMENTA COLETIVA}

O interesse pelo trabalho sobre representações como materialidades discursivas (nesse caso veiculadas em textos, fotografias, imagens forjadas nos cotidianos midiáticos) baseia-se na compreensão de que uma representação se constitui em uma forma de apresentar e, ao mesmo tempo, produzir ideias e sentidos para as relações sociais e culturais, influenciando e produzindo subjetividades. Segundo Silva (2000) as representações podem assumir

\footnotetext{
formas textuais e visuais através das quais se descrevem os diferentes grupos culturais e suas características. No contexto dos Estudos Culturais, a análise da representação concentra-se em sua expressão material como 'significante': um texto, uma pintura, um filme, uma fotografia. Pesquisam-se aqui, sobretudo, as conexões entre identidade cultural e representação, com base no pressuposto de que não existe identidade fora da representação" (SILVA, 2000, p.97).
}

A partir de representações presentes em artefatos culturais, entendidos aqui em sua força pedagógica e de invenção ou (re)produção estética, procuramos (o grupo pesquisadorextensionista) pelo que informava e contribuía para definir posições de sujeito e/ou tensionar 
uma cultura dada. Buscamos entender algo das relações que regulam o gênero e a sexualidade, especialmente na intersecção com a idade, a partir da influência política dos binarismos de gênero materializados nesses difusos meios de informação, socialização e de produção cultural que são as mídias na contemporaneidade e como essa produção é negociada com a cultura local. Isto é, como a idade funciona na ampliação ou na restrição das margens de liberdade dos sujeitos em relação a corpo, gênero e sexualidade.

Para isso recorremos às representações entendendo-as como (re)produtoras de pedagogias e tecnologias de gênero e (in)formantes para o exercício da sexualidade. Apoiados em De Lauretis (2007), entendemos que:

\begin{abstract}
A construção do gênero segue através de tecnologias de gênero múltiplas (o cinema, por exemplo) e de discursos institucionais (a teoria, por exemplo) que têm o poder de controlar o campo das significações sociais e, portanto, produzir, promover e -implantar representações de gênero. Entretanto, as condições de possibilidades de uma construção diferente do gênero também existem nas margens dos discursos hegemônicos. Situadas fora do contrato social heterossexual e inscritas nas práticas micropolíticas, elas podem contribuir para a construção do gênero e situam-se antes a um nível local de resistências na subjetividade e na auto-representação. (p.75-76).
\end{abstract}

A ferramenta que utilizamos em nosso processo de pesquisa-intervenção funcionou justamente nos interstícios ou nos "restos" discursivos do amplo lastro de tecnologias de gênero produzidas em nossa sociedade particular. De modo que nosso "instrumento" funcionou como um modo de perguntar/pesquisar sobre as representações disponíveis e veiculadas em meios de informação - revistas, jornais, campanhas publicitárias, programas de $\mathrm{TV}$, etc.

Para exemplificar tal constatação, apresentamos agora o planejamento e a execução de uma oficina com esta intencionalidade, assim como parte dos resultados da aplicação da metodologia junto a um grupo de meninas e meninos estudantes de uma escola pública federal em Florianópolis. A turma participante tinha idades entre 10 e 12 anos, constituindo-se em um grupo infanto/pré-juvenil. O grupo tinha a particularidade de um aluno portador de necessidades educativas especiais (portador de paralisia). O menino era acompanhado por uma professora auxiliar (presente durante todo o trabalho da oficina). As oficinas aconteceram a partir da divisão da turma, entre meninos e meninas. Em um dia, os meninos trabalharam conosco, enquanto as meninas participavam da atividade de educação física. No outro dia invertemos.

Durante a realização da última oficina o grupo foi reunido, embora ainda meninas e 
BOTANDO CORPO, (DES)FAZENDO GÊNERO.

UMA FERRAMENTA PARA A PESQUISA-INTERVENÇÃO NA EDUCAÇÃO

meninos trabalhassem separadamente. Cada grupo foi integrado por aproximadamente 12 integrantes. Note-se que ao trabalharmos com meninos ou meninas em separado ou em grupo misto, as duas possibilidades nos permitem tensionamentos referentes aos binarismos de gênero. No caso do exemplo que traremos aqui, a oficina foi realizada com grupos separados (ora com meninos, ora com meninas, finalizando com um encontro do grupo da turma, trabalhando sobre a inversão do material produzido/troca de papéis). A partir dessa proposta inicial oferecemos ao grupo a seguinte proposta:

$O$ quê: um espaço de discussão sobre representações de gênero, em perspectiva geracional - através das fases de vida infância, juventude, idade adulta e velhice. Nossa proposta de intervenção ofereceu às/aos participantes um espaço de reflexão sobre gênero e (inter)geracionalidades, a partir dos marcadores de classe, localidade e em relação ao exercício da sexualidade na busca ativa de representações midiatizadas.

Material: revistas (cabe salientar que aqui a perspectiva de acesso às revistas pode ser contingencial - o que a escola possui - ou intencional - a equipe de pesquisa propõe um meio de informação impresso, podendo ser o jornal mais lido pela comunidade, uma revista, etc. -, papel colorido, tesoura, cola, lã em cores diversas, papel Kraft, material de sucata, pincel atômico; aparelho de som, computador portátil (para registro no local sobre as falas) e máquina fotográfica (para o registro exclusivo do material produzido).

Como: criação do boneco (contornado em papel kraft, com folhas suficientemente largas para caber uma pessoa deitada) e a tatuagem das representações. Dividimos um grupo aleatoriamente (através da técnica de agrupamento por números aleatórios 1, 2, 3 e 4) e organizado em 4 subgrupos, cada um trabalhando sobre uma fase de vida (embora arbitrarias estas fases, nosso objetivo foi o de operar a partir delas para poder desmontá-las, desconstruílas): a infância, adolescência/juventude, idade adulta e velhice. Ao grupo é solicitado que busquem imagens que possam representar a historia de uma menina ou um menino. O grupo foi dividido com a tarefa de produzir dois corpos, pensando as várias fases de vida ou apenas uma ou outra. A construção de pelo menos duas foi posta em marcha e podemos visualizar o material em perspectiva comparatista. $\mathrm{O}$ trabalho poderia ocorrer seguramente apenas sobre uma representação geracional (ou a infância, a juventude, idade adulta e velhice), mas não o fizemos assim. Fizemos 4 figuras (grandes contornos de um corpo sobre papel), em distintos momentos da sua vida. A partir dessa figura "vazia", vamos "tatuar" nele representações de coisas que possam marcar esse tempo da vida (por exemplo, a infância) e preencheremos essa 
figura com imagens recortadas de revista, para marcar esse corpo com imagens que o apresentarão ao mundo (seus gostos, o lugar onde mora, com quem vive, seu contexto, etc.). E lhe demos também um rosto, foi esse nosso convite.

Feita a coleta (seleção) de imagens, a partir das imagens (recortes de imagens) disponibilizadas e devidamente coladas no contorno desses corpos em papel (um corpo contornado e sobre este contorno, a distância de um ou dois palmos, fez-se outro contorno, de forma a termos duas ou quatro lacunas/linhas a serem preenchidas), trocamos as figuras (passamos a figura do menino para as meninas e vice-versa) e solicitamos que construíssem uma história para esta pessoa, trazendo inicialmente algumas referências sobre ele: onde nasceu, em que ponto do bairro, região, quem são seis pais, irmãos, avós, tios, primos e outros familiares, o que fazem seus pais, sua origem étnica/localidade de origem dos pais, seus atributos físicos (possui ou não algum tipo de deficiência), religião, clube de futebol para o qual torce e outros marcadores identitários. Estimulamos ao grupo que pensasse no "jeito" desta menina ou deste menino: se é meiga/o, agitado/a, intempestivo/a, doce, quieto/a, arteira/o, etc., de acordo com as características das representações coletadas.

Em algum momento da construção da narrativa o grupo ao lado ofereceu algumas provocações a fim de produzir algum estranhamento e novidade na narrativa desta figura de pessoa que está sendo construída. Para isso, oferecemos um conjunto de questões prévias e questões "vazias", todas dispostas em uma urna e de acordo com especificidade da pesquisa que interessam aos proponentes. As questões preparadas serão definidas pelo grupo de oficineiras e oficineiros, a partir do perfil do grupo de jovens, com o objetivo de introduzir questões relativas aos temas de interesse na pesquisa (no caso, utilizamos as questões de interesse que compõem a proposta do projeto de extensão, como as lgbtfobias, sexismo, racismo, performances de gênero, exercício da sexualidade, conjugalidade, parentesco, etc.).

As questões "em branco" foram produzidas na hora pelos subgrupos de jovens, o que possibilitou a produção de problemáticas locais. De mesma forma, as oficineiras e os oficineiros (4 pessoas) estavam livres para interferir em pontos críticos da narrativa, sobretudo diante das situações que se referem a representações que exigem ser mais bem definidas e às situações que podem ser ampliadas para um melhor entendimento dessa narrativa.

Ao término dessa oficina a experiência foi avaliada com o grupo dos/das participantes, considerando-se a pertinência do trabalho, seus efeitos, as possibilidades e os limites; articulando o trabalho produzido como elemento para um diálogo com projeto pedagógico da 
BOTANDO CORPO, (DES)FAZENDO GÊNERO.

\section{UMA FERRAMENTA PARA A PESQUISA-INTERVENÇÃO NA EDUCAÇÃO}

escola e a realidade da comunidade escolar. O material foi fotografado, para trabalho posterior da equipe de pesquisa ${ }^{5}$, e o material produzido ficou à disposição da equipe da escola.

Iniciamos a terceira etapa da oficina de três dias oferecendo às meninas o trabalho que os meninos produziram e, de mesma forma, o trabalho que as meninas produziram para os meninos (meninas e meninos trabalharam em dias separados). Inicialmente uma recusa, afinal o trabalho dos meninos não ficou tão bom, afirmam algumas meninas. Decidimos manter nossa perspectiva e ocupamos a sala em suas pontas. O grupo de meninos em número maior entorno de 15 - ficam acompanhados pelas bolsistas do núcleo Ângela e Nathany, posicionadas no espaço em frente à lousa. $\mathrm{Na}$ sala também permanece a professora que auxilia o menino Mauricio, portador de necessidades educativas especiais. Os trabalhos são entregues e os grupos começam a trabalhar sobre a "sentença" produz uma historia de menina a mulher adulta e de menino a homem adulto.

A oficina transcorreu com muitas dificuldades em relação ao grupo de meninos. Eles falavam alto, disputam a palavra, o caminho da história, se impuseram com alguma agressividade. Essa imposição é tamanha que as meninas pedem para se afastar da sala, pois elas não conseguem se concentrar com o barulho que eles fazem. E saem juntamente com Kathyça e Bruno, para um espaço exterior. Foi notável a concentração e o empenho delas no trabalho, embora as disputas internas não tivessem sido menos frequentes. Sobretudo por Mariana e Daniela, as duas meninas mais articuladas da turma. Havia também disputa no grupo de meninas, mas elas eram menos "barulhentas" e mais resolvidas, sem recorrer a gritos ou empurrões, resolviam seus problemas discutindo. Algo bastante diferente dos meninos que deram às oficineiras do Núcleo de Pesquisa 'muito trabalho'. Sem contar que na sala havia a presença da professora titular, a professora de educação física e a professora assistente de Maurício. O que demanda das oficineiras mais empenho e plasticidade. Elas parecem exaustas, lutando para poder pegar alguma coisa compreensível dos meninos. Algo bastante diferente do grupo das meninas que, inclusive, se organizam de forma a elas mesmas escreverem a história proposta e de disputarem a escrita. De fato, uma disputa diferente daquela dos meninos.

\footnotetext{
${ }^{5}$ Nessa oficina contamos com a colaboração de uma equipe multidisciplinar de bolsistas NIGS, ação direta do Projeto Papo Sério. Colaboraram nas oficinas à época (2011) Ângela Medeiros, graduanda em Psicologia; Bruno Cordeiro, graduando em Ciências Sociais; Gabriela Santos, graduanda em Ciências Sociais; Kathilça Lopes, graduanda em Pedagogia; Nattany Rodrigues, graduanda em Serviço Social; e Raruilquer Oliveira, graduando em Ciências Sociais.
} 
Como provocador de interseccionalidade as oficineiras e os oficineiros tinham em cada grupo uma urna contendo palavras-chave, elaboradas anteriormente, significando os interesses das mesmas/ dos mesmos (os projetos individuais de cada bolsista): família, religião, esporte, aparência e relacionamentos, entre outros temas. Estes foram sorteados em momentos específicos da construção das narrativas. Apenas um ou dois temas, conforme combinado. O tema recorrente no sorteio casualmente foi religião. Ao que introduziram nas narrativas as alunas e alunos geralmente a religião católica, do tipo "e ele era católico". A oficineira Ângela, que se encontrava na coordenação do subgrupo de meninas, considerou que:

\begin{abstract}
Foi interessante também a naturalidade em que as meninas colocaram o garoto como negro, imaginei que poderia haver algum atrito quando defendeu-se a ideia de ele ser negro haja visto que em sua maioria elas eram brancas. Na minha época de ensino fundamental com certeza não deixariam que a criança fosse negra, entendo então que a discussão sobre a igualdade racial deve de alguma forma estar sendo feita com essa turma.
\end{abstract}

Os trabalhos poderiam seguir, mas tivemos de adequar-nos ao tempo. Voltamos todos para o espaço coletivo, afixamos as personagens e começamos as apresentações. O grupo de meninas é apresentado pelas duas lideranças Maria e Daniela. Daniela faz uma apresentação sobre os elementos que utilizaram para compor a história, fala do processo e como o fizeram. Maria se ocupa de ler a narrativa escrita. $\mathrm{O}$ tom é tranquilo e seguro e elas estão visivelmente mais organizadas. $\mathrm{O}$ produto reflete o processo. Os meninos apresentam-se em trio. Um trio composto por dois dos mais "terríveis" e um menino mais quieto. A história deles teve o apoio de registro de Maria, o que faz com que recorressem a palavras-chave e expressões anotadas pela colega para a elaboração de uma história contada no momento. Diferente das meninas, que organizaram o texto e a narrativa de forma a fixá-lo e torná-lo um texto mais coerente, sem muitas lacunas.

O texto dos meninos é de uma história fragmentada, com alguma linha de continuidade, mas sempre marcada por episódios fantásticos e com conotação sexual. Como o caso da personagem Julia que tem seu carro estragado no meio do caminho e o mesmo é consertado por um mecânico e a partir desse encontro, depois de que a chave de fendas tenha sido tocada pelas mãos dos dois, estabelece-se um caso de amor. A narrativa da menina envolve viagens, um filho promissor e rico, chamado Neymar, que depois vira mecânico, etc. Para a bolsista Kathylça: 


\begin{abstract}
A construção de uma história linear também foi mais difícil para os meninos, que não conseguiram escrever sobre a vida de "Júlia". As idéias brotavam de cada um deles e não conseguiam alinhavá-las em uma sequência. Até que dois meninos, Pedro e Daniel tomaram a frente da história. Junior, um menino magrinho também, mas com olhos grandes e intensos, começou baixinho e concentrado. Criou uma vida para "Júlia" do começo ao fim. Daniel ajudou com alguns detalhes da trama.
\end{abstract}

A oficina não tem mais muito tempo, para além das apresentações, mas oferecemos com os poucos minutos que nos restam a possibilidade de que alguém do próprio grupo possa acrescentar algo ou então que alguém do grupo "oposto", que pudesse fazer comentários sobre a narrativa e se ela estava a contento ou não do que produziram, isto é, se os colegas conseguiram dar uma vida aquele corpo de representações que foi produzido. Os comentários incluem desde a especificação de um nome que falta ou de um ponto da história que não ficou claro, até o ponto mais quente, que envolveu a palavra "sexo" e o nome de dois participantes escritos em um cartaz "um menino e uma menina". O que significou muitas inquietações sobre por que estavam escritos aqueles nomes. Possivelmente uma provocação relacionada a alguns arranjos amorosos no interior da sala de aula e que explodiram na oficina. A temática "sexo", presente o tempo todo nos materiais, provocou muitas discussões. Segundo Nattany:

\footnotetext{
Ao término das apresentações, as meninas questionaram bastante a coerência da história dos meninos, pedindo explicações sobre pontos incoerentes. Já os meninos se mostraram interessados em saber o por que as meninas haviam escrito "Sexo" no cartaz delas. Sobre essa última questão, a sala se mostrou um pouco constrangida, aliás incomodada com a pergunta, então nesse momento a equipe núcleo interviu ponderando que não se tratava de uma pergunta referente a quem escreveu, mas sim o porque que elas enquanto um todo haviam escrito tal palavra. Depois da intervenção, uma das meninas tomou a frente e disse: Colocamos porque mulheres adultas gostam/ costumam fazer sexo.
}

\title{
DESDOBRAMENTOS: NOTAS PARA CONCLUIR
}

Os encontros dessas oficinas produziram uma experiência de reflexão metodológica e conceitual importantes para um olhar sobre nosso próprio saber-fazer no campo da pesquisa e intervenções em gênero e sexualidade na escola, a partir da dimensão de interseccionalidades de marcadores sociais e diferença. A experiência exerceu uma dobra sobre nosso próprio 
pensar, sobre o investimento da pesquisa politicamente engajada e, sobretudo, na oportunidade de democratização dos métodos da pesquisa acadêmica, em uma relação de horizontalidade (mesmo que as pesquisadoras/ pesquisadores portem consigo histórico de apropriação sobre os temas), criando assim a possibilidade de alguma ampliação nas margens de liberdade, movimentando e agitando o pensamento crítico diante das pedagogias e programas curriculares institucionais. Os regimes normativos de gênero e as prescrições da sexualidade cercam a experiência cotidiana dos processos educativos. Pesquisa-intervir pode funcionar no sentido de alerta a que estamos ativamente envolvidos na disputa destes processos de (re)significação cotidianos.

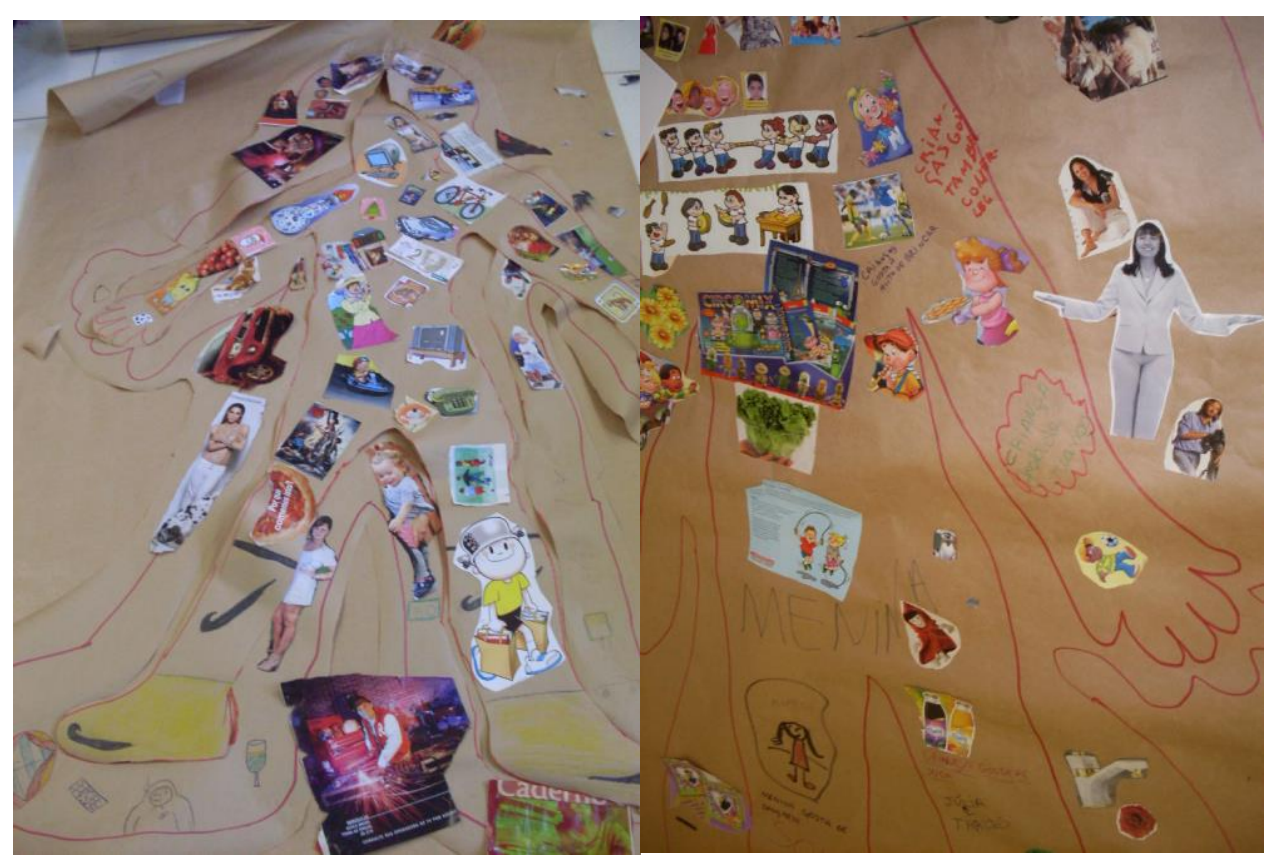

Material produzido pelo grupo de meninos em uma oficina em escola pública.

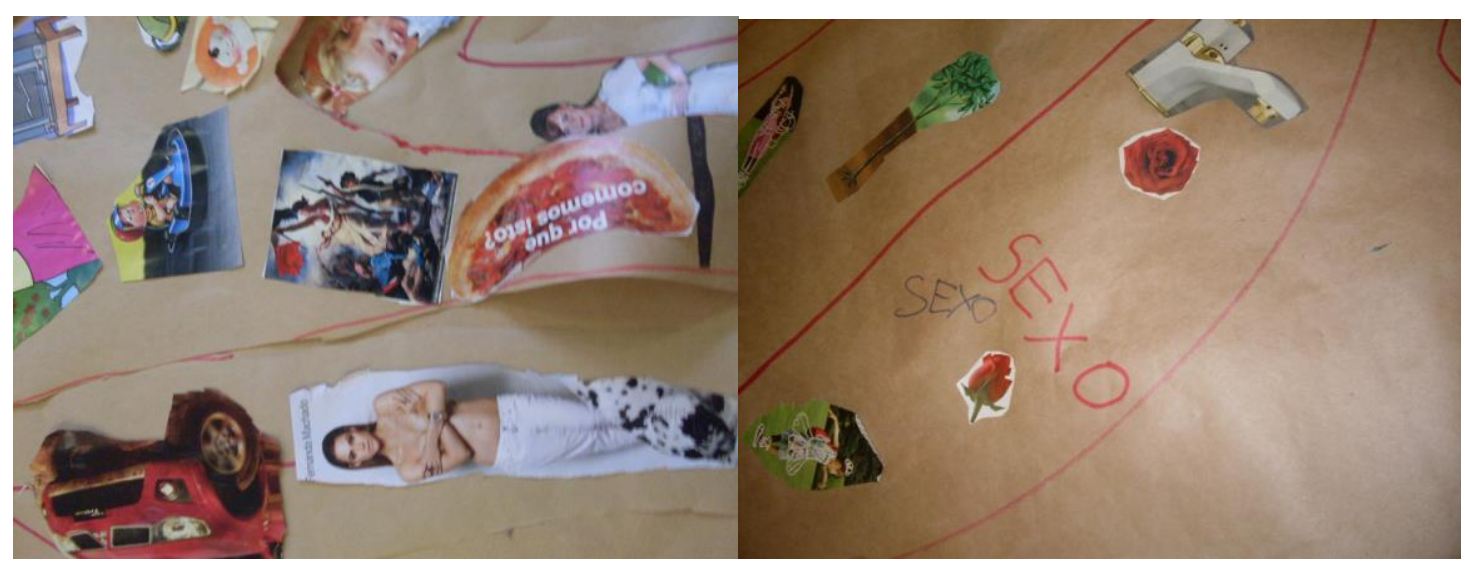

Material produzido pelo grupo de meninos em uma oficina em escola pública. 


\title{
GROWING UP, (UN)DOING GENDER. A TOOL FOR INTERVENTION RESEARCH IN EDUCATION
}

\begin{abstract}
This paper presents the methodological course of an intervention research in the field of school education, with emphasis on the study of gender relations, sexuality and generations in intersectionality with other marks of identity and difference. This study sought to understand how certain subject positions are produced and what mechanisms of intelligibility and negotiations of meanings are present in certain contexts of schooling. As such, the research was carried out in the tactical perspective of reversibility of the forms of objectification of subjectivity and social inequalities resulting from these discourses through the use of intervention research. The results of this methodological work suggest that intervention research can work for alert we are actively involved in the management of processes significance of body, gender and sexuality daily.
\end{abstract}

Keywords: Body; Gender; Sexuality; Intersectionalities; Education

\section{ECHANDO CUERPO, (DES)HACIENDO GÉNERO. UNA HERRAMIENTA PARA LA INVESTIGACIÓN-INTERVENCIÓN EN LA EDUCACIÓN}

\section{Resumen}

Este artículo presenta el trayecto de experimentación de una metodología de investigaciónintervención en el campo de la educación escolar, con énfasis en el estudio de las relaciones de género, sexualidad y generaciones en interseccionalidades con otros marcadores sociales de identidad y diferencia. Se buscó, con el presente estudio, comprender cómo determinadas posiciones de sujeto se producen y qué mecanismos de inteligibilidad y negociaciones de significados se encuentran presentes en determinados contextos de la educación escolar, al mismo tiempo en que nos alojamos en la perspectiva táctica de la reversibilidad de las formas de 
objetivación de las subjetividades y de las desigualdades sociales resultantes de estos discursos a través de la investigación-intervención. Los resultados de este trabajo metodológico sugieren que la investigación-intervención puede trabajar en pro de alerta que estamos involucrados activamente en la gestión de los procesos de significacion del cuerpo, del género y de la sexualidad cotidianas.

Palabras clave: Cuerpo; Género; Sexualidad; Interseccionalidades; Educación

\section{REFERÊNCIAS}

AGUIAR, K; ROCHA, M. L. Pesquisa-Intervenção e a Produção de Novas Análises. Psicologia, Ciência e Profissão, 23 (4), (p. 64-73), 2003.

ALVES, Nilda. Decifrando o pergaminho - o cotidiano das escolas nas lógicas das redes cotidianas. In: ALVES, N.; OLIVEIRA, I. B. Pesquisa no/do cotidiano das escolas - sobre redes de saberes. Rio de Janeiro; DP\&A, 2001.

BILGE, Sirma. Théorisations féministes de l'intersectionnalité. Diogène, $\mathrm{n}^{\circ} 225$, janviermars, 2009.

BUTLER, Judith. Défaire le genre. Paris: Éditions Amsterdam, 2006.

. Trouble dans le genre. Pour un féminisme de la subversion. Paris: La Découvert, 2005.

COSTA, Marisa Vorraber. Caminhos investigativos III: riscos e possibilidades de pesquisar nas fronteiras. Rio de Janeiro: DP\&A, 2005.

COSTA, M. V.; SILVEIRA, Rosa Hessel.; SOMMER, Luis Henrique. Estudos culturais, educação e pedagogia. Revista Brasileira de Educação, Maio-ago, n23, p. 36-61, 2003.

LAURETIS, Theresa. Théorie queer et cultures populaires. De Foucault à Cronemberg. Paris: La Dispute, 2006.

FOUCAULT, Michel. O sujeito e o poder. In: DREYFUS, H.; RABINOW, P. Michel Foucault: uma trajetória filosófica - para além do estruturalismo e da hermenêutica. Rio de Janeiro: Forense Universitária, p. 231-149, 1995.

. Foucault. In: Foucault, M. Dits et écrits II, 1976-1988. Paris: Gallimard, 2001.

2006.

. Defender la sociedad. Buenos Aires Fondo de cultura económica de Argentina, 
BOTANDO CORPO, (DES)FAZENDO GÊNERO.

GIROUX, Henri. A. Memória e pedagogia no maravilhoso mundo da Disney. In: SILVA, T. T. (org.) Alienígenas na sala de aula. Uma introdução aos estudos culturais em educação. 9a ed., Petrópolis: Vozes. 2011.

GROSSI, Miriam Pillar (org). Representações de Iniciação Sexual e Homossexualidades em Escolas do Ensino Público de Santa Catarina. Florianópolis: Núcleo de Identidades de Gênero e Subjetividades/ Universidade Federal de Santa Catarina; PN DST/HIV/AIDS Ministério da Saúde, 2009.

LAGRAVE, Rose-Marie. Ré-enchanter la vieillesse. Mouvements, $\mathrm{n}^{\circ}$ 59, juillet-septembre. La Découvert: Paris, 2009.

LOURO, Guacira Lopes. Pedagogias da sexualidade. I: LOURO, G. L. O corpo educado. Pedagogias da Sexualidade. Belo Horizonte: Autêntica Editora, 2010.

. Um corpo estranho. Ensaios sobre sexualidade e teoria queer. Belo Horizonte: Autêntica, 2004.

. Heteronormatividade e Homofobia. In: JUNQUEIRA, R. (Org.). Diversidade Sexual na Educação: problematizações sobre a homofobia nas escolas. Brasília: Ministério da Educação/SECAD, 2009.

MARASCHIN, Cleci. Pesquisar e intervir. Psicologia e Sociedade. vol.16, n.1, p. 98-107, 2004.

MEYER, D. E; DAMICO, J. O corpo como marcador social saúde, beleza e valoração de cuidados corporais de jovens mulheres. Revista Brasileira de Ciências do Esporte, v. 27, n. 3, maio, p. 103-118, 2006.

POCAHY, Fernando Altair. A idade um dispositivo. A geração como performativo. Provocações discursivo-desconstrucionistas sobre corpo-gênero-sexualidade. Revista Polis e Psique, Dossiê Sexualidade, GT Psicologia e Sexualidade, ANPPEP - Associação Nacional de Pesquisa e Pós-Graduação em Psicologia, 2012.

POCAHY, F. A.; NARDI, H. C.. Saindo do armário e entrando em cena: juventudes, sexualidades e vulnerabilidade social. Revista de Estudos Feministas, v. 7, p. 45-66, 2007.

ROCHA, Marisa Lopes. Psicologia e Educação: resgate de produção de histórias. In: JACÓVILELA, A M; JABUR, F; RPDRIGUES, H. B. C. (Org.). Clio-psyché: história da Psicologia no Brasil. Rio de Janeiro: UERJ/ NAPE, 1999.

Educação em tempos de tédio: um desafio à micropolítica. In: Souza, M. P. R. ; Tanamachi, E.; Rocha, M. L. (Orgs.). Psicologia e Educação. 2 ed. São Paulo: Casa do Psicólogo, v. 1, p. 185-207, 2002.

SILVA, Tomaz Tadeu. A produção social da identidade e da diferença. In: SILVA, T. T. (org.). Identidade e diferença: a perspectiva dos estudos culturais. Rio de Janeiro: Vozes, 2007, $7^{\mathrm{a}}$ ed. 
. Teoria Cultural e Educação - um vocabulário crítico. Belo Horizonte: Autêntica, 2000.

SPIVAK, Gayatri Chakravorty. Literatura. Cadernos Pagu. n.19, p. 9-53, 2002.

Data de recebimento: 06/01/2016

Data de aceite: 29/02/2016 